\title{
DISPERSION AND VOLATILITY IN STOCK RETURNS: AN EMPIRICAL INVESTIGATION
}

\author{
John Y. Campbell \\ Martin Lettau
}

\author{
Working Paper 7144 \\ http://www.nber.org/papers/w7144 \\ NATIONAL BUREAU OF ECONOMIC RESEARCH \\ 1050 Massachusetts Avenue \\ Cambridge, MA 02138 \\ May 1999
}

We are grateful to Sangjoon Kim for his contributions to the first version of this paper, Campbell, Kim, and Lettau (1994). We thank an anonymous referee and Rene Stulz for useful comments. Jung-Wook Kim and Matt Van Vlack provided able research assistance. The views expressed herein are those of the authors and do not necessarily reflect the views of the National Bureau of Economic Research, the Federal Reserve Bank of New York, or the Federal Reserve System.

(C) 1999 by John Y. Campbell and Martin Lettau. All rights reserved. Short sections of text, not to exceed two paragraphs, may be quoted without explicit permission provided that full credit, including (C) notice, is given to the source. 
Dispersion and Volatility in Stock Returns:

An Empirical Investigation

John Y. Campbell and Martin Lettau

NBER Working Paper No. 7144

May 1999

\section{ABSTRACT}

This paper studies three different measures of monthly stock market volatility: the time-series volatility of daily market returns within the month; the cross-sectional volatility or "dispersion" of daily returns on industry portfolios, relative to the market, within the month; and the dispersion of daily returns on individual firms, relative to their industries, within the month. Over the period 1962-97 there has been a noticeable increase in firm-level volatility relative to market volatility. All the volatility measures move together in a countercyclical fashion. While market volatility tends to lead the other volatility series, industry-level volatility is a particularly important leading indicator for the business cycle.

John Y. Campbell Department of Economics Harvard University Littauer Center Cambridge, MA 02138 and NBER jyc@mit.edu
Martin Lettau

Federal Reserve Bank of New York 33 Liberty Street New York, NY 10045-0001

Martin.Lettau@ny.frb.org 


\section{Introduction}

It is by now a commonplace observation that the volatility of the aggregate stock market is not constant, but changes over time. Economists have built increasingly sophisticated statistical models to capture this time-variation in volatility. Simple filters such as the rolling standard deviation used by Officer (1973) have been replaced by parametric $\mathrm{ARCH}$ or stochastic-volatility models. Partial surveys of the enormous literature on these models are given by Bollerslev et al. (1992), Hentschel (1995), and Campbell, Lo, and MacKinlay (1997, Chapter 12).

Aggregate volatility is of course important in almost any theory of risk and return, and it is the volatility experienced by holders of aggregate index funds. But the aggregate market return is only one component of the return to an individual stock. Industry-level and idiosyncratic firm-level shocks are also important components of individual stock returns. There are several reasons to be interested in the volatilities of these components.

First, many investors have large holdings of individual stocks; they may choose not to diversify in the manner recommended by financial theory, or their holdings may be restricted by corporate compensation policies. These investors are affected by shifts in industry-level and idiosyncratic volatility, just as much as by shifts in market volatility. Second, arbitrageurs who trade to exploit mispricing of individual stocks face risks that are related to idiosyncratic return volatility, not aggregate market volatility. Larger pricing errors are possible when idiosyncratic firm-level volatility is high (Ingersoll 1987, Chapter 7, Shleifer and Vishny 1997). Third, firm-level volatility is important in event studies. Events affect individual stocks, and the statistical significance of abnormal event-related returns is determined by the volatility of individual stock returns relative to the market or industry (Campbell, Lo, and MacKinlay 1997, Chapter 4). Fourth, the price of an option on an individual stock depends on the total volatility of the stock return, including industry-level and idiosyncratic volatility as well as market volatility.

Disaggregate volatility measures also have important relations with aggregate output in some macroeconomic models. Models of sectoral reallocation, following Lilien (1982), imply that an increase in the industry-level volatility of productivity growth may reduce output as resources are diverted from production to costly reallocation across sectors. Models of "cleansing recessions" (Caballero and Hammour 1994, Eden and Jovanovic 
1994) emphasize similar effects at the level of the firm. An exogenous increase in the arrival rate of information about management quality may temporarily reduce output as resources are reallocated from low-quality to high-quality firms; alternatively, a recession which occurs for some other reason may reveal information about management quality and increase the pace of reallocation across firms.

There is surprisingly little empirical research on volatility at the level of the industry or firm. A few papers use disaggregate data to study the "leverage" effect, the tendency for volatility to rise following negative returns (Black 1976, Christie 1982, Duffee 1995). Engle and Lee (1993) use a factor ARCH model to study the persistence properties of firm-level volatility for a few large stocks. Some researchers have used stock-market data to test macroeconomic models of reallocation across industries or firms (Bernard and Steigerwald 1993, Brainard and Cutler 1993, Loungani et al. 1990), or to explore the firm-level relation between volatility and investment (Leahy and Whited 1996). Malkiel and $\mathrm{Xu}$ (1995), following the first version of this paper (Campbell, Kim, and Lettau 1994), study long-run trends in disaggregate volatility. Roll (1992) and Heston and Rouwenhorst (1994) decompose volatility in industry and country-specific effects and study the implications for international diversification.

The purpose of this paper is to provide a simple summary of historical movements in market-, industry-, and firm-level volatility. To keep things as simple as possible, we average industry-level volatility across industries, and idiosyncratic firm-level volatility across firms. We report a few results for individual industries but none for individual firms.

In the interest of simplicity we also use daily data within each month to construct sample variances for that month, without imposing any parametric model to describe the evolution of variances over time. Multivariate volatility models are notoriously complicated and difficult to estimate. Furthermore, while the choice of a parametric model may be essential for volatility forecasting, it is less important for describing historical movements in volatility because all models tend to produce historical fitted volatilities that move closely together. The reason for this was first given by Merton (1980) and was elaborated by Nelson (1992): with sufficiently high-frequency data, volatility can be estimated arbitrarily accurately over an arbitrarily short time interval. Recently Ander- 
sen et al. (1999) have used a similar approach to produce daily exchange rate volatilities from intradaily data on exchange rate movements.

Our results can be summarized as follows. Besides the volatility of the market, industry-level and, especially, firm-level volatility are important components of the total volatility of the return of a typical firm. All three volatility measures experience substantial variations over time. They are positively correlated as well as autocorrelated. Over our 1962-97 sample period, firm-level volatility has a significant positive trend whereas market-level and industry-level volatility do not. Thus the idiosyncratic risk of a typical stock has increased over time relative to its systematic market or industry risk; equivalently, the explanatory power of market or industry models for individual stocks has declined over time.

We also study the lead-lag relations among our volatility measures and various indicators of the state of the aggregate economy. Granger-causality tests suggest that market volatility tends to lead the other volatility series. All three volatility measures increase substantially in economic downturns and tend to lead recessions. To explore this effect in detail, we run OLS regressions of GDP growth on the three volatility measures lagged by one quarter. We also include other variables which are known to forecast GDP, such as its own lag and the return of the CRSP value-weighted portfolio. All three volatility variables - but particularly industry-level volatility-help to forecast economic activity and reduce the significance of other commonly used forecasting variables.

The organization of the paper is as follows. Section 2 discusses data construction, Section 3 presents basic empirical results, Section 4 studies the cyclical properties of our volatility measures, Section 5 presents selected results for individual industries, and Section 6 concludes. 


\section{Data Construction}

\subsection{Methodology}

We decompose the return on a "typical" stock into three components: the market-wide return, an industry-specific residual, and a firm-specific residual. Based on this return decomposition, we construct time-series of volatility measures of the three components for a typical firm. Our goal is to define volatility measures that sum to the total return volatility of a typical firm, without having to keep track of covariances and without having to estimate betas for firms or industries. In this subsection, we discuss how we can achieve such a representation of volatility. The next subsection presents the estimation procedure and some details of the data sample.

Industries are denoted by an $i$ subscript while individual firms are indexed by $j$. The simple excess return of firm $j$ that belongs to industry $i$ in period $t$ is denoted as $R_{i j t}$. This excess return, like all others in the paper, is measured relative to the contemporaneous Treasury bill rate. Let $w_{i j t}$ be the weight of firm $j$ in industry $i$. In principle, our methodology is valid for any arbitrary weighting scheme, however in the application below we use a value-weighting based on market capitalization. The excess return of industry $i$ in period $t$ is given by $R_{i t}=\sum_{j \in i} w_{i j t} R_{i j t}$. Industries are aggregated correspondingly. The weight of industry $i$ in the total market is denoted by $w_{i t}\left(=\sum_{j \in i} w_{i j t}\right)$ and the excess market return is $R_{m t}=\sum_{i} w_{i t} R_{i t}$.

The next step is the decomposition of firm and industry returns into the three components. We first write down a decomposition based on the CAPM, and we then modify it for empirical implementation. The CAPM implies that we can set intercepts to zero in the following equations:

$$
R_{i t}=\beta_{m i} R_{m t}+\tilde{\epsilon}_{i t}
$$

for industry returns and

$$
R_{i j t}=\beta_{m j} R_{m t}+\beta_{i j} \tilde{\epsilon}_{i t}+\tilde{\eta}_{i j t},
$$

for individual firm returns. ${ }^{1}$ In (1) $\beta_{m i}$ denotes the beta for industry $i$ with respect to the market return, and $\tilde{\epsilon}_{i t}$ is the industry-specific residual. Similarly, in $(2) \beta_{m j}$ is the

\footnotetext{
${ }^{1}$ We could work with the market model, not imposing the mean restrictions of the CAPM, and allow free intercepts $\alpha_{i}$ and $\alpha_{i j}$ in equations (1) and (2). However our goal is to avoid estimating firm-specific
} 
beta of firm $j$ with respect to the market, $\beta_{i j}$ is the beta of firm $j$ in industry $i$ with respect to its industry shock, and $\tilde{\eta}_{i j t}$ is the firm-specific residual. The weighted sum of the different betas equals unity:

$$
\sum_{i} w_{i t} \beta_{m i}=1, \quad \sum_{j \in i} w_{i j t} \beta_{m j}=1, \quad \sum_{j \in i} w_{i j t} \beta_{j i}=1
$$

The CAPM decomposition (1) and (2) guarantees that the different components of a firm's return are orthogonal to one another. Hence it permits a simple variance decomposition in which all covariance terms are zero:

$$
\begin{gathered}
\operatorname{Var}\left(R_{i t}\right)=\beta_{m i}^{2} \operatorname{Var}\left(R_{m t}\right)+\operatorname{Var}\left(\tilde{\epsilon}_{i t}\right), \\
\operatorname{Var}\left(R_{i j t}\right)=\beta_{m j}^{2} \operatorname{Var}\left(R_{m t}\right)+\beta_{i j}^{2} \operatorname{Var}\left(\tilde{\epsilon}_{i t}\right)+\operatorname{Var}\left(\tilde{\eta}_{i j t}\right) .
\end{gathered}
$$

The problem with this decomposition, however, is that it requires knowledge of firmspecific betas which are difficult to estimate and may well be unstable over time. Therefore we work with a simplified model that does not require any information about betas. We show that this model permits a variance decomposition similar to (4) and (5) on an appropriate aggregate level.

First, consider the following simplified industry return decomposition which drops the industry beta coefficient $\beta_{m i}$ from (1):

$$
R_{i t}=R_{m t}+\epsilon_{i t}
$$

Equation (6) defines $\epsilon_{i t}$ as the difference between the industry return $R_{i t}$ and the market return $R_{m t}$. Campbell, Lo, and MacKinlay (1997, Chapter 4, p.156) refer to (6) as a "market-adjusted-return model" in contrast to the market model of equation (1).

Comparing (1) and (6), we have

$$
\epsilon_{i t}=\tilde{\epsilon}_{i t}+\left(\beta_{m i}-1\right) R_{m t}
$$

The market-adjusted-return residual $\epsilon_{i t}$ equals the CAPM residual of (4) only if the industry beta $\beta_{m i}=1$ or $R_{m t}=0$.

parameters; despite the well-known empirical deficiencies of the CAPM, we feel that the zero-intercept restriction is reasonable in this context. 
The apparent drawback of this decomposition is that $R_{m t}$ and $\epsilon_{i t}$ are not orthogonal, and so one cannot ignore the covariance between them. Computing the variance of the industry return yields

$$
\begin{aligned}
\operatorname{Var}\left(R_{i t}\right) & =\operatorname{Var}\left(R_{m t}\right)+\operatorname{Var}\left(\epsilon_{i t}\right)+2 \operatorname{Cov}\left(R_{m t}, \epsilon_{i t}\right) \\
& =\operatorname{Var}\left(R_{m t}\right)+\operatorname{Var}\left(\epsilon_{i t}\right)+2\left(\beta_{m i}-1\right) \operatorname{Var}\left(R_{m t}\right),
\end{aligned}
$$

where taking account of the covariance term once again introduces the industry beta into the variance decomposition.

Note, however, that although the variance of an individual industry return contains covariance terms, the weighted average of variances across industries is free of the individual covariances:

$$
\begin{aligned}
\sum_{i} w_{i t} \operatorname{Var}\left(R_{i t}\right) & =\operatorname{Var}\left(R_{m t}\right)+\sum_{i} w_{i t} \operatorname{Var}\left(\epsilon_{i t}\right) \\
& =\sigma_{m t}^{2}+\sigma_{\epsilon}^{2},
\end{aligned}
$$

where $\sigma_{m t}^{2} \equiv \operatorname{Var}\left(R_{m t}\right)$ and $\sigma_{\epsilon t}^{2} \equiv \sum_{i} w_{i t} \operatorname{Var}\left(\epsilon_{i t}\right)$. The terms involving betas aggregate out since from (3) $\sum_{i} w_{i t} \beta_{m i}=1$. Therefore we can use the residual $\epsilon_{i t}$ in (6) to construct a measure of average industry-level volatility that does not require any estimation of betas. The weighted average $\sum_{i} w_{i t} \operatorname{Var}\left(R_{i t}\right)$ can be interpreted as the expected volatility of a randomly drawn industry (with the probability of drawing industry $i$ equal to its weight $w_{i t}$ ).

We can proceed in the same fashion for individual firm returns. Consider a firm return decomposition that drops betas from (2):

$$
R_{i j t}=R_{m t}+\epsilon_{i t}+\eta_{i j t},
$$

where $\epsilon_{i t}$ is defined in (7) and

$$
\eta_{i j t}=\tilde{\eta}_{i j t}+\left(\beta_{m j}-1\right) R_{m t}+\left(\beta_{i j}-1\right) \tilde{\epsilon}_{i t} .
$$

Just as with industry residuals, $\eta_{i j t}=\tilde{\eta}_{i j t}$ only if firm betas equal one or market and industry shocks are zero.

The variance of the firm return is

$$
\begin{aligned}
\operatorname{Var}\left(R_{i j t}\right)= & \operatorname{Var}\left(R_{m t}\right)+\operatorname{Var}\left(\epsilon_{i t}\right)+\operatorname{Var}\left(\eta_{i j t}\right) \\
+ & 2 \operatorname{Cov}\left(R_{m t}, \epsilon_{i t}\right)+2 \operatorname{Cov}\left(\epsilon_{i t}, \eta_{i j t}\right)+2 \operatorname{Cov}\left(R_{m t}, \eta_{i j t}\right) .
\end{aligned}
$$


We can express the covariances in terms of betas and volatilities:

$$
\begin{aligned}
\operatorname{Cov}\left(\epsilon_{i t}, \eta_{i j t}\right) & =\operatorname{Cov}\left(\tilde{\epsilon}_{i t}+\left(\beta_{m i}-1\right) R_{m t}, \tilde{\eta}_{i j t}+\left(\beta_{m j}-1\right) R_{m t}+\left(\beta_{i j}-1\right) \tilde{\epsilon}_{i t}\right) \\
& =\left(\beta_{i j}-1\right) \operatorname{Var}\left(\tilde{\epsilon}_{i t}\right)+\left(\beta_{m i}-1\right)\left(\beta_{m j}-1\right) \operatorname{Var}\left(R_{m t}\right), \\
\operatorname{Cov}\left(R_{m t}, \eta_{i j t}\right) & =\left(\beta_{m j}-1\right) \operatorname{Var}\left(R_{m t}\right) .
\end{aligned}
$$

The weighted average of firm variances in industry $i$ is therefore

$$
\sum_{j \in i} w_{i j t} \operatorname{Var}\left(R_{i j t}\right)=\operatorname{Var}\left(R_{m t}\right)+\operatorname{Var}\left(\epsilon_{i t}\right)+\sigma_{\eta i t}^{2}+2\left(\beta_{m i}-1\right) \operatorname{Var}\left(R_{m t}\right),
$$

where $\sigma_{\eta i t}^{2} \equiv \sum_{j \in i} w_{i j t} \operatorname{Var}\left(\eta_{i j t}\right)$ is the weighted average of firm-level volatility in industry $i$. Computing the weighted average across industries yields again a variance decomposition without any betas since the industry betas sum to one:

$$
\begin{aligned}
\sum_{i} w_{i t} \sum_{j \in i} w_{i j t} \operatorname{Var}\left(R_{i j t}\right) & =\operatorname{Var}\left(R_{m t}\right)+\sum_{i} w_{i t} \operatorname{Var}\left(\epsilon_{i t}\right)+\sum_{i} w_{i t} \sigma_{\eta i t}^{2} \\
& =\sigma_{m t}^{2}+\sigma_{\epsilon t}^{2}+\sigma_{\eta t}^{2}
\end{aligned}
$$

where $\sigma_{\eta t}^{2} \equiv \sum_{i} w_{i t} \sigma_{\eta i t}^{2}=\sum_{i} w_{i t} \sum_{j \in i} w_{i j t} \operatorname{Var}\left(\eta_{i j t}\right)$ is the weighted average of firm-level volatility across all firms. As in the case of industry returns, the simplified decomposition of firm returns (10) yields a measure of average firm-level volatility that does not require estimation of betas.

We can gain further insight into the relation between our volatility decomposition and that based on the CAPM if we aggregate the latter (equations (4) and (5)) across industries and firms. When we do this we find that

$$
\sigma_{\epsilon t}^{2}=\tilde{\sigma}_{\epsilon t}^{2}+\operatorname{CSV}_{t}\left(\beta_{m i}\right) \sigma_{m t}^{2},
$$

where $\tilde{\sigma}_{\epsilon t}^{2} \equiv \sum_{i} w_{i t} \operatorname{Var}\left(\tilde{\epsilon}_{i t}\right)$ is the average variance of the CAPM industry shock $\tilde{\epsilon}_{i t}$, and $\operatorname{CSV}_{t}\left(\beta_{m i}\right) \equiv \sum_{i} w_{i t}\left(\beta_{m i}-1\right)^{2}$ is the cross-sectional variance of industry betas across industries. Similarly,

$$
\sigma_{\eta t}^{2}=\tilde{\sigma}_{\eta t}^{2}+\operatorname{CSV}_{t}\left(\beta_{m j}\right) \sigma_{m t}^{2}+\operatorname{CSV}_{t}\left(\beta_{i j}\right) \tilde{\sigma}_{\epsilon t}^{2}
$$

where $\tilde{\sigma}_{\eta t}^{2} \equiv \sum_{i} w_{i t} \sum_{j \in i} w_{i j t} \operatorname{Var}\left(\tilde{\eta}_{i j t}\right), \operatorname{CSV}_{t}\left(\beta_{m j}\right) \equiv \sum_{i} w_{i t} \sum_{j} w_{i j t}\left(\beta_{m j}-1\right)^{2}$ is the crosssectional variance of firm betas on the market across all firms in all industries, and 
$\operatorname{CSV}_{t}\left(\beta_{i j}\right) \equiv \sum_{i} w_{i t} \sum_{j} w_{i j t}\left(\beta_{i j}-1\right)^{2}$ is the cross-sectional variance of firm betas on industry shocks across all firms in all industries.

Equations (17) and (18) show that cross-sectional variation in betas can produce common movements in our variance components $\sigma_{m t}^{2}, \sigma_{\epsilon t}^{2}$, and $\sigma_{\eta t}^{2}$, even if the CAPM variance components $\tilde{\sigma}_{\epsilon t}^{2}$ and $\tilde{\sigma}_{\eta t}^{2}$ do not move at all with the market variance $\sigma_{m t}^{2}$. We return to this issue later in the paper.

\subsection{Estimation}

We use the firm-level return data in the CRSP data set to estimate the volatility components in (16) based on the return decomposition (6) and (10). We aggregate individual firms into 49 industries according to the classification scheme in Fama and French (1997). ${ }^{2}$ We refer to their paper for the SIC classification. Our sample period runs from July 1962 to December 1997. Obviously, the composition of firms in individual industries has changed dramatically over the sample period. The total number of firms covered by the CRSP data set increased from 2047 in 62:7 to 8927 in 97:12. The industry with the most firms on average over the sample is Financial Services with 6884 (253 in 62:7 to 16873 in 97:12) while the industry with the fewest firms is Defense with 86 (13 to 140 over the sample). Based on market capitalization the three largest industries on average over the sample are Petroleum/Gas (11\%), Financial Services (7.8\%) and Utilities (7.4\%). Table 9 includes a list of the ten largest industries. To get daily excess return, we subtract the 30-day T-bill return divided by number of trading days in a month.

We use the following procedure to estimate the three volatility components in (16). Let $s$ denote the frequency at which returns are measured. We will use daily returns for most estimates but also consider weekly and monthly returns to check the sensitivity of our results with respect to the return frequency. Using returns of frequency $s$ we construct volatility estimates of frequency $t$. Unless otherwise noted $t$ refers to months and $s$ to days in this paper. To estimate the variance components in (16) we use timeseries variation of the individual return components within each period $t$. The sample volatility of the market return in period $t$, which we denote from now on as $\mathrm{MKT}_{t}$, is

\footnotetext{
${ }^{2}$ They actually use 48 industries but we group the firms which are not covered in their scheme in an additional industry.
} 
computed as

$$
\mathrm{MKT}_{t}=\hat{\sigma}_{m t}^{2}=\sum_{s \in t}\left(R_{m s}-\mu_{m}\right)^{2},
$$

where $\mu_{m}$ is defined as the mean of the $R_{m s}$ over the sample. ${ }^{3}$ To be consistent with the methodology presented above, we construct the market returns as the weighted average using all firms in the sample in a given period. The weights are based on market capitalization. Although this market index differs slightly from the value-weighted index provided in the CRSP data set, the correlation is almost perfect at 0.997. For weights in period $t$ we use the market capitalization of a firm in period $t-1$ and take the weights as constant within period $t$.

For volatility in industry $i$ we sum the squares of the industry-specific residual in (6) within a period $t$ :

$$
\hat{\sigma}_{\epsilon i t}^{2}=\sum_{s \in t} \epsilon_{i s}^{2}
$$

As shown above, we have to average over industries to ensure that the covariances of individual industries cancel out. This yields the following measure for average industry volatility $\mathrm{IND}_{t}$ :

$$
\mathrm{IND}_{t}=\sum_{i} w_{i t} \hat{\sigma}_{\epsilon i t}^{2}
$$

Estimating firm-specific volatility is done in a similar way. First we sum the squares of the firm-specific residual in (10) for each firm in the sample:

$$
\hat{\sigma}_{\eta i j t}^{2}=\sum_{s \in t} \eta_{i j s}^{2}
$$

Next, we compute the weighted average of the firm-specific volatilities within an industry:

$$
\hat{\sigma}_{\eta i t}^{2}=\sum_{j \in i} w_{i j t} \hat{\sigma}_{\eta i j t}^{2}
$$

and lastly we average over industries to obtain a measure of average firm-level volatility $\mathrm{FIRM}_{t}$ as

$$
\mathrm{FIRM}_{t}=\sum_{i} w_{i t} \hat{\sigma}_{\eta i t}^{2}
$$

As for industry volatility this procedure ensures that the firm-specific covariances cancel out.

\footnotetext{
${ }^{3}$ We also experimented with time-varying means but the results are almost identical.
} 


\section{Empirical Results}

\subsection{A First Look at Dispersion and Volatility}

Before plunging into econometric analysis, consider first the plots of market volatility MKT, industry-level volatility IND and firm-level volatility FIRM in Figures 1 to 3. The top panel shows the raw monthly time-series while the bottom panel plots a lagged moving average of order 12 . Note that the scales on the $y$-axes differ in each figure.

Market-level volatility shows the well-known patterns that have been studied by countless papers on the time-variation of index return variances. Comparing the monthly series with the smoothed version in the bottom panel suggests that market volatility has a slow-moving component along with a fair amount of high-frequency noise. Market volatility was particularly high around 1970, in the mid-70's, around 1980 and towards the end of the sample. Of course, the stock market crash in October 1987 caused an enormous spike in market volatility which is cut off in the plot. The value of MKT in $10 / 87$ is 0.056 , about six times as high as the second highest value. The plot also shows the NBER dated recessions shaded in grey. A casual look at the plot suggests that market volatility increases in recessions. We will study the cyclical behavior of MKT and the other volatility measures below.

Next, consider the behavior of industry volatility IND in Figure 2. Compared with market volatility, industry volatility is slightly lower on average. As for MKT, there is a slow-moving component and some high-frequency noise. IND was particularly high in the mid-70's and around 1980. It is also noteworthy that the effect of the crash in October 1987 is quite significant for IND, although not as much as for MKT. More generally, industry volatility seems to increase during macroeconomic downturns.

Lastly, Figure 3 plots firm-level volatility FIRM. The first striking feature is that FIRM is on average much higher than MKT and IND. This implies that firm-specific volatility is the largest component of the total volatility of an average firm. The second important characteristic of FIRM is that it trends up over the sample. The plots of MKT and IND do not exhibit any visible upward slope while for FIRM it is clearly visible. This indicates that the stock market has become more volatile over the sample but on a firm level instead of a market or industry level. We will analyze this issue in 
some detail below. Apart from the trend, the plot of FIRM looks similar to MKT and IND. Firm-level volatility seems to be higher in NBER-dated recessions and the crash also has a significant effect.

Looking at the three volatility plots together, it is clear that the different volatility measures tend to move together, particularly at lower frequencies. For example, all three volatility measures increase during the oil price shocks in the early to mid-1970s. However, there are also some periods in which the volatility measures move differently. For example, IND is very high compared to its long-term mean during the early 1980's while MKT and FIRM remain fairly low during this period. Another interesting episode is the last year of our sample. Market volatility increased significantly in 1997 while IND and FIRM did not. We will study the comovement of the three series below.

It is obvious from the plots that the stock market crash in October 1987 had a significant effect on all three volatility series. This raises the issue whether this one-time event might overshadow the rest of the sample and distort some of the results. To avoid this we report many results for both the raw data set and a "winsorized" version where we replace the October 1987 observation with the second largest observation in the data set. This procedure decreases the magnitude of the crash but leaves it as an important event in the sample.

\subsection{Stochastic versus Deterministic Trends}

The possibility of increased stock market volatility in recent decades has attracted attention in both the academic literature and the popular press. Using our decomposition of return volatility we can not only establish whether the return on a typical stock has become more volatile, but we can also ask what are the sources of increased volatility. But first we have to establish whether any potential trend is stochastic or deterministic in nature. The plots suggest that all our volatility measures exhibit a fairly high amount of positive autocorrelation, a fact that is well-known for market volatility. This raises the possibility of unit roots in the series.

To check this we employ augmented Dickey and Fuller (1979) tests. These tests include higher-order autoregressive terms in the regression to account for serial correlation. The test consists of regressing the series under investigation on its lagged value 
and lagged difference terms. The number of lagged differences to be included can be determined by the standard $t$-test of significance on the last lagged difference term. In Table 1 , the $\rho$-test is the augmented Dickey-Fuller test, and the $t$-test is based on OLS estimates using the estimated standard errors under the null hypothesis of a unit root. Either statistic can be used to test the hypothesis of the presence of unit root in the series under investigation. The table also presents the number of lagged difference terms included in the regression estimated for the unit root tests. The hypothesis of a unit root is rejected for all three volatility series at the $5 \%$ level against several plausible alternative stationary autoregressive processes whether we include or exclude the crash. Note that the rejection is weakest for firm-level volatility.

After rejecting the unit root hypothesis, we report some descriptive statistics and trend regressions in Table 2. The top panel presents results for daily volatility series while the two following panels report results for volatility series based on weekly and monthly returns, respectively. Consider first the absolute magnitudes of the volatility components in our benchmark sample based on daily returns. The annualized mean of MKT is about 0.015 which implies an annual standard deviation of $12.3 \%$. IND has a slightly lower mean of 0.010 implying an annual standard deviation of about $10 \%$, while FIRM is on average substantially larger than both MKT and IND with a mean of 0.064 implying an annual standard deviation of $25 \%$. These numbers imply that over the whole sample the share of the total unconditional variance that is due to the market variance, or the $R^{2}$ of a market model, is only about $17 \%$. Thus industry and in particular firm uncertainty are important components of the total volatility of an average firm. The means for the winsorized data are of course somewhat lower since the the crash is replaced by the second largest observation.

As can be seen from the plots all three volatility measures exhibit substantial variation over time. The second row in Table 2 reports unconditional standard deviations of the variance series. Market and firm volatility are more variable over time than industry volatility, but a large portion of the time-series variation in market volatility is due to the crash in October 1987. Taking the crash out of the sample reduces the standard deviation of market volatility by $60 \%$. The crash has much smaller effects on industry and firm volatility. 
Now we revisit the issue of trends. In Table 1 we rejected the unit root hypothesis for all three volatility series. An alternative hypothesis is the existence of a deterministic linear time trend. Table 2 reports regressions of the volatility series on deterministic trends. The $t$-statistics are Newey-West corrected with the optimal lag length chosen according to Newey and West (1994). The trend regression for daily data confirms the visual evidence from the plots. MKT and IND have a small positive trend coefficient which is weakly significant for IND. The trend in FIRM is much larger and strongly significant. Note that the large trend coefficient does not depend on whether the crash is included or not. Using the point estimates of the coefficients for winsorized data implies that firm-level volatility has more than doubled over the sample, while MKT and IND have increased by only about one third. Thus the increase in total volatility (which has also roughly doubled over the sample) is almost entirely due to the higher level of firm volatility. Another way to make the same point is to note that the share of FIRM volatility in total winsorized volatility has increased from $65 \%$ to $76 \%$ while the shares of MKT and IND have decreased from $20 \%$ to $14 \%$ and $15 \%$ to $10 \%$, respectively.

Table 2 also reports standard deviations of the detrended volatility series. A time trend biases the unconditional time-series variation upwards. Since FIRM has the largest trend among the three measures, the standard deviation decreases the most when the data are detrended. The effects of detrending are modest for MKT and IND. Even for detrended data, however, FIRM exhibits the greatest time-series variation once the effect of the crash is controlled through winsorization.

It is well known that daily stock returns exhibit a significant amount of serial correlation. This might affect our volatility series, in particular if the pattern of serial correlation is changing over our sample period (Froot and Perold (1995) document that autocorrelations of individual daily stock returns have fallen in the post-war period). To check the robustness of the results based on daily returns, we construct volatility series based on weekly and monthly returns for which autocorrelation is much weaker. Panels 2 and 3 in Table 2 show that the means of MKT and IND increase somewhat for longer horizon returns, confirming the fact that daily index and industry returns are positively autocorrelated. Firm-specific returns, by contrast, are negatively autocorrelated since the mean of FIRM decreases when weekly and monthly returns are used. These findings 
are consistent with French and Roll (1986) who show that daily returns of individual stocks are slightly negatively autocorrelated. The return horizon also affects the OLS coefficient in the trend regressions. The weekly and monthly series have a lower trend than the daily series. The point estimate of the trend coefficient for weekly market volatility is even negative (but insignificant) in the winsorized data. It is also interesting to note that winsorization has little effect on IND and FIRM once weekly or monthly returns are used. This suggests that industry and firm returns took a few days to adjust after the crash but within a week the effect of the crash died out at the industry and firm level.

We perform two additional sensitivity checks. As noted above, the number of firms in the data set has more than quadrupled over the sample. Thus many smaller firms are now listed on stock markets. To see how this influences our results, we compute the volatility series using only the 2047 largest firms (the minimum number of firms in a month of our sample). The results are shown in the panel denoted "large firms". In contrast to MKT and IND, which are not much affected by the exclusion of smaller firms, the mean and trend of FIRM are somewhat lower for large firms. However, the trend of FIRM is still positive and highly significant. The effect of firm size can also be seen in the last panel on Table 2 which reports results for equally-weighted series. As in the large-firm case, MKT and IND are not affected much by the weighting scheme. However, the impact on FIRM is enormous. The mean is five times larger than for the value-weighted series, and the standard deviation is eight times larger. Moreover, the trend coefficient increases about twelve-fold. The point estimates imply that firm-level volatility is about 30 times higher in 1997 than in 1962 for an average firm (chosen among all firms with equal probability). This demonstrates the significant effect on volatility of many small firms entering the market over our sample period.

\subsection{Covariation and Lead-Lag Relationships}

Besides the trend, two other aspects of the three volatility measures can be seen in Figures 1 to 3: they tend to move together contemporaneously and each series appears to exhibit a significant amount of serial correlation. These features of the data are examined in Table 3, both for raw and detrended winsorized data. The contemporaneous 
correlations among the series are around 0.7 and even slightly higher for detrended data. The table also shows that the series have positive and slowly decaying autocorrelations. Detrending reduces the autocorrelations significantly for FIRM, but has little effect for MKT and IND.

Table 4 asks how important the three volatility components are relative to the total volatility of an average firm. First, consider the mean. Over the whole sample, market volatility accounts for about $16 \%$ of the unconditional mean of total winsorized volatility, while IND accounts for $12 \%$. However, by far the largest portion of total volatility is firm-level volatility with about $72 \%$. Consistent with the observation of trends in the three series, the share of firm-level volatility has increased from $71 \%$ in the first 12 months of the sample to $77 \%$ in the last 12 months.

A variance decomposition using winsorized data shows that most of the time-series variation in total volatility is due to variation in MKT and FIRM. Industry volatility is more stable over time. The two largest components are FIRM variance and the covariation of MKT and FIRM; together they account for about $60 \%$ of the total timeseries variation in volatility. The market component by itself is much less important, only $15 \%$ of the total variation in volatility. Relative to its mean, however, MKT shows the greatest time-series variation.

Given the substantial low-frequency variation in our volatility measures, it may be of interest to isolate the longer-run movements. One crude way to do this is to compute moving averages as we did in the lower panels of Figures 1 to 3. Of course, this approach is ad hoc. An alternative natural way to smooth the series is to decompose each volatility time series into an expected and an unexpected part:

$$
\sigma_{t}^{2}=E_{t-1} \sigma_{t}^{2}+\xi_{t}
$$

We compute the conditional expectation of each volatility series by regressing it on its own lag and lags of the other series. We choose a lag length of four when forming the conditional expectations based on significance of individual lags.

At the bottom of Table 4 we report a variance decomposition for the conditional expectations of the volatility series. This puts even more weight on the terms involving FIRM; about $80 \%$ of the total variation is due to variance and covariance terms of 
FIRM. The contribution of MKT is below 10\%. The industry-level terms for conditional expectations are more or less unchanged compared to the raw data.

One issue that arises in interpreting these results is whether the common variation in MKT, IND, and FIRM might be explained by cross-sectional variation in betas. In equation (17), we showed that movements in MKT might produce variation in IND if betas differ across industries and the volatility of industries' CAPM residuals is independent of MKT. Under this hypothesis, the coefficient in a regression of IND on MKT would equal the cross-sectional variance of betas across industries. Empirically, the regression coefficient is 0.27 in our full sample while a direct estimate of cross-sectional variance of industry betas is only 0.03 ; this calculation suggests that cross-sectional variation in betas cannot explain more than a small fraction of the common movement in MKT and IND. A similar calculation based on equation (18) gives the same result for covariation between FIRM and the other two volatility measures. In our full sample, a regression of FIRM on MKT and IND gives coefficients of 0.72 and 1.40 respectively, much too large to be explained by plausible cross-sectional variation in firms' beta coefficients.

As a final exercise in this section, we ask whether the volatility measures help to forecast each other. Table 5 investigates this question using Granger-causality tests. The top panel reports $p$-values for bivariate VARs while the bottom panel uses trivariate VARs including all three series. The data are detrended and winsorized. The lag-length was chosen using the Akaike information criterion. In bivariate VARs MKT appears to Granger-cause both IND and FIRM at very high significance levels. IND does not help to predict MKT or FIRM but FIRM helps significantly to forecast MKT and IND. Much of the causality survives in trivariate systems. MKT Granger-causes IND and FIRM (although at lower significance levels than in the bivariate case). FIRM Granger-causes MKT but the effect on IND is now insignificant. IND fails to Granger-cause the other series as in the bivariate case. 


\section{Cyclical Behavior}

Studies of financial volatility in relation to the business cycle have historically focused on the volatility of a broad stock market index, i.e. market volatility. Schwert (1989) presents an extensive analysis of the relation of market volatility with economic activity confirming Officer's (1973) earlier results that market volatility is higher in economic downturns. In response to Officer (1973), Christie (1982) argues that this effect is due to increased financial leverage in recessions. However, Schwert (1989) shows that leverage by itself cannot account for the strong negative correlation of market volatility with economic activity. More recently, Hamilton and Lin (1996) model the joint behavior of stock returns and industrial production growth in a more sophisticated regime-switching model. They find that economic recessions are the single most important factor for explaining market volatility accounting for about $60 \%$ of its movements. In this section we extend the Schwert (1989) results and study the cyclical behavior of market, industry and firm-level volatility. As mentioned before, a casual look at the plots of the series suggests that all three volatility components tend to be higher in recessions (recall that the NBER dated recessions are shaded in grey). Now we characterize this relation more rigorously.

We start by reporting simple correlations of the volatility series with NBER business cycle dates in the top panel of Table 6. The table reports correlations of the volatility series at various lags with a variable that is set to 1 in NBER dated expansions and 0 in recessions. Hence a negative correlation implies that volatility tends to be higher in recessions. In addition to correlations for the raw series we also include results for conditional expectations and innovations of volatility (all series are detrended and winsorized). Consider first the raw series. All lead and lag correlations up to a year are negative, hence stock market volatility at the market, industry and firm level is higher in economic contractions. All three raw series have a strongly negative contemporaneous correlation between -0.420 for MKT and -0.508 for FIRM. The correlation is decreas-

ing in absolute value when volatility is lagged or led (we highlighted the most negative correlation in each column in bold). Among the three volatility measures, FIRM tends to have the most negative correlation with NBER dates. The pattern for conditional expectations is more or less the same as for the raw data. The values tend to be slightly 
more negative than for the raw data which is not surprising since the the conditional expectations are less noisy. The innovations of volatility are also negatively correlated with NBER dates. But in contrast to the raw data and conditional expectations, the correlations peak (in absolute value) when innovations lead the NBER dates by three months. This pattern holds for all three volatility measures. These results are consistent with Whitelaw (1994) who analyzes the properties of conditional expectations and innovations of market volatility in more detail.

These results provide strong evidence that market, industry, and firm-level volatility are all higher in economic downturns. But how big are the magnitudes? For raw data, the level of market volatility is about three times as high in NBER dated recessions as in expansions. While this ratio is surprisingly high, Schwert (1989) shows that it is even higher if the Great Depression is included in the sample. Industry-level and firm-level volatility roughly double in recessions. Recessions have a somewhat smaller effect on the predictable component of volatility; for conditional expectations, MKT is about 1.9 times higher in recessions than in booms, IND about 1.6 times and FIRM about 1.5 times.

While the NBER dates provide a benchmark case, some useful information is probably lost in the binary NBER classification scheme. Therefore, we next study the cyclical behavior of volatility using GDP data. GDP is measured on a quarterly frequency, hence we construct new volatility series on that frequency. We use daily returns within each quarter as before. The quarterly series behave very much like the monthly ones. The pattern of correlations of volatility with GDP growth, in the bottom panel of Table 6, is almost identical to the pattern of correlations with NBER dates. All volatility series are negatively correlated with GDP growth up to a lead and lag of about one year. The absolute values of the correlations are somewhat lower than before; this is not surprising given the noisiness of GDP data. As before, innovations in volatility show the highest correlation (in absolute value) leading GDP growth by one quarter.

After establishing that all three volatility measures move countercyclically, we now ask whether they have any power to forecast GDP growth. In Table 7 we present the results of OLS regressions with GDP growth as a dependent variable. As regressors we use lagged GDP growth and the lagged return on the value-weighted CRSP index as 
well as combinations of lagged volatility series. All $t$-statistics are Newey-West corrected with the optimal lag length chosen according to Newey and West (1994). The volatility series are detrended and winsorized. Regressing GDP growth on its own lag and the lagged CRSP index return yields an $R^{2}$ of $14 \%$. Both variables are individually significant. Next, we add each of the lagged volatility measures in turn. Each is individually significant and the $R^{2}$ increases to around $20 \%$. Interestingly, each volatility variable drives out the return of the CRSP value-weighted portfolio while lagged GDP growth remains significant.

Next, we include pairs of volatility variables as regressors. Since all three series are positively correlated it is not surprising that the individual significance levels are lower when more than one volatility series is included. While none of them is individually significant, they are strongly jointly significant. The $p$-values for $F$-tests that all coefficients of the volatility variables are zero are between $0.2 \%$ and $0.8 \%$. Furthermore, the $R^{2}$ 's increase to up to $22.2 \%$ when IND and FIRM are included in the regression. The results are similar when all three volatility variables are included. None of them is individually significant but the joint significance level is $0.6 \%$. There is no conclusive evidence which of the three volatility measures has the most forecasting power, but the $t$-values of IND are slightly higher (in absolute value) than those of MKT and FIRM and the $R^{2}$ is higher once IND is included in the regression. ${ }^{4}$

\footnotetext{
${ }^{4}$ We have also checked whether the correlation of the volatility series and led GDP growth translates to any power of GDP growth in forecasting volatilities. However, regressions of this type did not show any significance of lagged GDP growth.
} 


\section{Individual Industries}

So far we have studied volatilities averaged over industries. While such aggregated volatility measures contain information about an average industry, there is obviously a lot of variation across industries. The nature and composition of the industries in our sample differ tremendously, and there is little reason to believe that industry and firm-level volatility in the agricultural sector behave in the same way as volatility in the computer industry. To get some idea about the behavior of volatility in individual industries we study the ten largest industries separately in this section. The industries are selected according to their average weight (based on market capitalization) over the entire sample. Table 9 lists the individual industries by weight.

Constructing volatility measures for individual industries requires an adjustment in our estimation procedure. In section 2 we showed that the three return components in (10) are orthogonal when we average over firms and industries. Once we study individual industries we no longer average over industries. Therefore, we have to alter the return composition in the following way. Consider a decomposition which includes a beta for each industry:

$$
\begin{aligned}
R_{i t} & =\beta_{m i} R_{m t}+\tilde{\epsilon}_{i t} \\
R_{i j t} & =\beta_{m i} R_{m t}+\tilde{\epsilon}_{i t}+\eta_{i j t}^{*}
\end{aligned}
$$

Note that $R_{m t}$ and $\epsilon_{i t}$ are by construction orthogonal and therefore the volatility of the industry return is

$$
\operatorname{Var}\left(R_{i t}\right)=\beta_{m i}^{2} \operatorname{Var}\left(R_{m t}\right)+\tilde{\sigma}_{i t}^{2},
$$

where $\tilde{\sigma}_{i t}^{2}$ is the variance of $\tilde{\epsilon}_{i t}$. We still sum over all firms in the industry. Therefore we have for the average firm volatility in industry $i$ (from (15)):

$$
\sum_{j \in i} w_{i j t} \operatorname{Var}\left(R_{i j t}\right)=\beta_{m i}^{2} \operatorname{Var}\left(R_{m t}\right)+\tilde{\sigma}_{i t}^{2}+\sigma_{\eta i t}^{2 *}
$$

where $\sigma_{\eta i t}^{2 *}$ is the variance of $\eta_{i j t}^{*}$. Therefore we can use the residuals $\tilde{\epsilon}_{i t}$ in (26) and $\eta_{i j t}^{*}$ in (27) to construct industry and firm-level volatility for individual industries without having to estimate covariances or firm-level betas. The only additional parameters to be 
estimated are the industry betas on the market $\beta_{m i}$. We use OLS regressions assuming that the betas are constant over the sample.

Table 9 reports results for the ten largest industries in the sample. Petroleum/Gas is the largest industry in our sample with an average share of $11 \%$ of the total market capitalization over the whole sample period followed by financial services and utilities. Most of the large industries have an industry-beta of around unity, with the exception of utilities and telecommunications firms which have a substantially lower beta. Next, consider the descriptive statistics of industry and firm-level volatility. As in the aggregated data FIRM is on average substantially larger the IND. However, the means of IND vary much more from industry to industry than do the means of FIRM. For example, the mean of IND for utilities is only about one-third of IND in aggregated data. The spread for firm-level volatility is much lower. Overall industries with a high average industry-level volatility also tend to have a high firm-level volatility (the correlation of the means of IND and FIRM across industries is 0.323). Moreover, large industries tend to have low IND and FIRM on average (the correlations of industry weights with the means of IND and FIRM are -0.394 and -0.491).

Previously we established the existence of an upward trend in FIRM volatility for aggregated data. Now we ask whether individual industries also exhibit significant trends in volatility. First, we perform unit root tests on all industry and firm volatility series. The results are not reported here but we reject the unit root hypothesis for all industries. In regressions on a linear time trend, six of the ten largest industries show a significant positive trend in IND while two have a significant negative trend. Among all 49 industries 16 (12) have a significant positive (negative) trend. This confirms the finding that the properties of industry-level volatility vary considerably among industries. The picture for FIRM is more uniform. We find that the time trend coefficient is significantly positive for seven of the ten largest industries and 27 out of all 49 industries, while none of the ten largest industries and only four industries in the entire sample exhibit a negative trend. We do not attempt to interpret the results for individual industries in detail, but it might not be surprising that the telecommunications, computer, and retail sectors exhibit a particularly large upward trend in firm-specific volatility. We should stress that this fact is not due to an unusual increase in the number of listed firms in these industries. The 
time trend in the sample that includes only large firms (see the discussion of Table 2 for details of this sample) shows the same large trend in firm-level volatility for these industries.

In the previous section, we showed that aggregate volatility measures are strongly countercyclical and are able to forecast aggregate GDP growth. Now we examine whether there are similar patterns on the level of individual industries. Since output data for individual industries are only available on an annual basis we convert all volatility series accordingly. The output data were obtained from the BLS and range from 1972 to 1997. Data for industry 23 (miscellaneous manufacturing) and 49 (miscellaneous firms) were not available. To construct industry-specific output data we first regress the output growth rate in industry $i, \Delta y_{i t}$, on total industrial output growth $\Delta y_{t}$. Denote the industry specific residual $\nu_{i t}$. Table 10 reports simple correlations of $\nu_{i t}$ with contemporaneous and one-period lagged industry and firm-specific volatility for the ten largest industries. Almost all of the correlations are negative indicating that industry and firm-level volatility are countercyclical even at the industry level. A similar picture holds for the sample of all industries. For IND, 33 (14) of the 47 industries have a negative (positive) contemporaneous correlation with industry output, and 36 (11) have a negative (positive) correlation when volatility is lagged relative to output. For FIRM, the corresponding numbers are 36 (11) and 35 (12), respectively.

Next, we investigate whether the volatility components have forecasting power for future industry-specific output. As regressors we use lagged values of the industry output residual, the return on the industry portfolio, and the three aggregate volatility measures as well as industry and firm-specific volatility in the particular industry. The annual sample contains 26 years of data, hence separate estimation for each industry is not feasible. We therefore pool the data cross-sectionally and perform a restricted estimation. For an industry $i$, consider the following regression:

$$
\begin{aligned}
\nu_{i t}= & \alpha_{0}+\alpha_{1} \nu_{i t-1}+\alpha_{2} R_{i t-1}+ \\
& \alpha_{3} M K T_{t-1}+\alpha_{4} I N D_{t-1}+\alpha_{5} F_{I R M_{t-1}+} \\
& \alpha_{6} I N D_{i t-1}+\alpha_{7} F I R M_{i t-1}+\omega_{i t},
\end{aligned}
$$

where $R_{i t}$ is the return on the industry portfolio, and $I N D_{i t-1}$ and $F I R M_{i t-1}$ are indus- 
try and firm-level volatilities computed from the decomposition (26) and (27). We stack all industries into a single system and estimate the model imposing the restriction that the coefficients are identical across all industries. Using Newey-West corrected standard errors, we find that the only significant variable is firm-specific volatility in the industry. The point estimate of $\alpha_{7}$ is -0.158 with a $t$-statistic of -2.345 . However, the $R^{2}$ of the regression is only $1.2 \%$ indicating that industry-specific output residuals are very noisy.

The forecasting power increases somewhat if we use raw industry output data instead of residuals. While the above specification constructs pure industry effects net of aggregate output, it cannot be used to forecast industry output since aggregate output in period $t$ is not known at time $t-1$. We therefore use the following pooled regression:

$$
\begin{aligned}
\Delta Y_{i t}= & \alpha_{0}+\alpha_{1} \Delta Y_{i t-1}+\alpha_{2} \Delta Y_{t-1}+\alpha_{3} R_{i t-1}+ \\
& \alpha_{4} M K T_{t-1}+\alpha_{5} I N D_{t-1}+\alpha_{6} F I R M_{t-1}+ \\
& \alpha_{7} I N D_{i t-1}+\alpha_{8} F I R M_{i t-1}+\omega_{i t} .
\end{aligned}
$$

As for the industry output residuals, the coefficient on industry-level FIRM is significantly negative. The point estimate is $\alpha_{8}=-0.190$ with a $t$-statistic of -2.559 . The only other significantly variable is lagged output growth: $\alpha_{1}=0.216$ with a $t$-statistic of 3.996. The $R^{2}$ is $6.3 \%$ which is still moderate but significantly larger than in the regression using output residuals. Despite the modest forecasting power, it is interesting to note that firm-level volatility in a given industry is significantly negatively related to future output growth in that industry. 


\section{Conclusion}

In this paper we have tried to characterize the behavior of stock market volatility — not only at the level of the market as a whole, but also at the industry and idiosyncratic firm levels. Our approach has two characteristic features.

First, we have used daily data to construct monthly volatility which we then treat as observable. This allows us to use standard econometric methods to describe the timeseries variation of volatility, rather than the more advanced methods that are necessary when volatility is treated as an unobserved latent variable. Andersen et al. (1999) use a similar approach to study volatility in the foreign exchange market. Second, we define volatility components in such a way that we can construct the total volatility of a typical firm by adding up components, without regard to covariance terms, and yet we avoid the estimation of industry or firm-level beta coefficients. Both these features can be modified in future research, but they help enormously in the initial exploration of the data.

Our main results are as follows. First, in our 1962-97 sample period there is no evidence that any of our volatility components have stochastic trends; but there is strong evidence of a positive deterministic trend in idiosyncratic firm-level volatility. This trend is not due merely to an increase in the number of publicly traded companies, or to changes in the serial correlation of daily data. It implies that the $R^{2}$ of a market model or market-industry model for a typical stock has been declining over time.

Second, firm-level volatility both accounts for the greatest share of total firm volatility on average, and for the greatest share of the movements over time in total firm volatility. Relative to its mean, however, market volatility displays the greatest variation over time.

Third, industry-level volatility tends to be more stable than the other volatility components and those components help to forecast its movements over time.

Fourth, all the components of volatility are countercyclical and tend to lead variations in GDP. The volatility measures help to forecast GDP growth and greatly diminish the significance of stock index returns in forecasting GDP.

Finally, we obtain broadly similar results when we disaggregate to the level of individual industries, using estimates of industry betas on the aggregate market but still avoiding the estimation of firm-level betas. 


\section{References}

Andersen, T.G., T. Bollerslev, F.X. Diebold, and P. Labys, 1999, "The Distribution of Exchange Rate Volatility", unpublished paper, Northwestern University, Duke University, and University of Pennsylvania.

Bernard, A.B. and D.G. Steigerwald, 1993, "Cleansing Recessions: Evidence from Stock Prices", working paper, MIT and UC Santa Barbara.

Black, F., 1976, "Studies of Stock Price Volatility Changes", Proceedings of the 1976 Meetings of the Business and Economic Statistics Section, 177-181, American Statistical Association.

Bollerslev, T., R. Chou, and K. Kroner, 1992, "ARCH Modeling in Finance: A Review of the Theory and Empirical Evidence", Journal of Econometrics 52, 5-59.

Brainard, S.L. and D.M. Cutler, 1993, "Sectoral Shifts and Cyclical Unemployment Reconsidered", Quarterly Journal of Economics 108, 219-243.

Caballero, R.J. and M. Hammour, 1994, "The Cleansing Effect of Recessions", American Economic Review 84, 1350-1368.

Campbell, J.Y., 1996, "Understanding Risk and Return", Journal of Political Economy 104, 298-345.

Campbell, J.Y., S. Kim, and M. Lettau, 1994, "Dispersion and Volatility in Stock Returns: An Empirical Investigation", unpublished paper, Princeton University.

Campbell, J.Y., A.W. Lo, and A.C. MacKinlay, 1997, The Econometrics of Financial Markets, Princeton University Press, Princeton, NJ.

Campbell, J.Y. and P. Perron, 1991, "Pitfalls and Opportunities: What Macroeconomists Should Know about Unit Roots," NBER macroeconomics annual, Blanchard, O.J and S. Fischer, eds., MIT Press, Cambridge and London, 141-201.

Christie, A., 1981, "The Stochastic Behavior of Common Stock Variances: Value, Leverage, and Interest Rate Effects", Journal of Financial Economics 10, 407-432. 
Duffee, G.R., 1995, "Stock Returns and Volatility: A Firm-Level Analysis", Journal of Financial Economics 37, 399-420.

Eden, B. and B. Jovanovic, 1994, "Asymmetric Information and the Excess Volatility of Stock Prices", Economic Inquiry 32, 228-235.

Engle, R.F. and G.G.J. Lee, 1993, "Long Run Volatility Forecasting for Individual Stocks in a One Factor Model", unpublished paper, University of California at San Diego.

Fama, E.F. and K.R. French, 1997, "Industry Costs of Equity", Journal of Financial Economics 43, 153-194.

Ferson, W.E. and C.R. Harvey, 1991, "The Variation of Economic Risk Premiums", Journal of Political Economy 99, 385-415.

French, Kenneth and Richard Roll, 1986, "Stock Return Variances: The Arrival of Information and the Reaction of Traders". Journal of Financial Economics 19, 3-30.

Froot, Kenneth and Andre Perold, 1995, "New Trading Practices and Short-Run Market Efficiency". Journal of Futures Markets 15, 731-765.

Hamilton, J.D. and G. Lin, 1996, "Stock Market Volatility and the Business Cycle", Journal of Applied Econometrics 11, 573-593.

Hentschel, L., 1995, "All in the Family: Nesting Symmetric and Asymmetric GARCH Models", Journal of Financial Economics 39, 71-104.

Heston, Steven L. and K. Geert Rouwenhorst, 1994, "Does Industrial Structure Explain the Benefits of International Diversification?" Journal of Financial Economics 36, 3-27.

Leahy, J.V. and T.M. Whited, 1996, "The Effect of Uncertainty on Investment: Some Stylized Facts", Journal of Money, Credit, and Banking 28, 64-83. 
Loungani, P., M. Rush, and W. Tave, 1990, "Stock Market Dispersion and Unemployment", Journal of Monetary Economics 25, 367-388.

Malkiel, B.G. and Y. Xu, 1995, "The Structure of Stock Market Volatility", unpublished paper, Princeton University.

Merton, R.C., 1980, "On Estimating the Expected Return on the Market: An Exploratory Investigation", Journal of Financial Economics 8, 323-361.

Nelson, D., 1992, "Filtering and Forecasting with Misspecified ARCH Models I: Getting the Right Variance with the Wrong Model", Journal of Econometrics 52, 61-90.

Newey, Whitney and Kenneth D. West, 1994, "Automatic Lag Selection in Covariance Matrix Estimation," Review of Economic Studies 61, 631-654.

Officer, R.R., 1973, "The Variability of the Market Factor of the New York Stock Exchange", Journal of Business 46, 434-453.

Roll, Richard, 1992, "Industrial Structure and the Comparative Behavior of International Stock Market Indices", The Journal of Finance 47, 3-42.

Schwert, G.W., 1989, "Why Does Stock Market Volatility Change Over Time?", Journal of Finance 44, 1115-1153.

Shleifer, A. and R.W. Vishny, "The Limits of Arbitrage", Journal of Finance 52, 35-55.

Whitelaw, Robert F., 1994, "Time Variations and Covariations in the Expectation and Volatility of Stock Market Returns", The Journal of Finance 49, 515-41. 
TABLE 1

Unit Root Tests

raw winsorized

\begin{tabular}{l|ccc|ccc} 
& MKT & IND & FIRM & MKT & IND & FIRM \\
\hline $\begin{array}{l}\text { constant } \\
\rho \text {-test } \\
t \text {-test }\end{array}$ & -328 & -103 & -80.3 & -175 & -88.5 & -46.5 \\
lag order & -12.17 & -4.59 & -3.98 & -8.55 & -4.28 & -3.29 \\
\hline $\begin{array}{l}\text { constant \& trend } \\
\rho \text {-test }\end{array}$ & & 5 & 5 & 1 & 4 & 5 \\
$t$-test & -330 & -125 & -145 & -177 & -91.7 & -79.1 \\
lag order & -12.24 & -5.60 & -6.35 & -8.60 & -4.36 & -4.34 \\
\hline
\end{tabular}

Note: This table reports unit root tests for monthly volatility series constructed from daily data. $\rho$-test is the Dickey-Fuller test statistic. Critical values at the $5 \%$ level are -8.00 when a constant is included in the regression and -21.5 when a constant and a linear trend are included. The $5 \%$ critical values for the $t$-test under the null hypotheses of a unit root are -2.87 with a constant and -3.42 with a constant and a trend. The number of lags is determined by the 'general to specific' method recommended in Campbell and Perron (1991). 
TABLE 2

Descriptive Statistics and Linear Trends

\begin{tabular}{|c|c|c|c|c|c|c|}
\hline & \multicolumn{3}{|c|}{ raw } & \multicolumn{3}{|c|}{ winsorized } \\
\hline & MKT & IND & FIRM & MKT & IND & FIRM \\
\hline $\begin{array}{l}\text { daily } \\
\text { mean } * 100 \\
\text { std. dev. } * 100 \\
\text { std. dev. } * 100 \text { detrended } \\
\text { linear trend } * 10^{5}\end{array}$ & $\begin{array}{c}1.542 \\
1.009 \\
1.007 \\
0.156 \\
(1.287) \\
\end{array}$ & $\begin{array}{c}1.032 \\
0.119 \\
0.119 \\
0.062 \\
(1.934) \\
\end{array}$ & $\begin{array}{c}6.436 \\
0.840 \\
0.732 \\
0.965 \\
(7.126) \\
\end{array}$ & $\begin{array}{c}1.409 \\
0.424 \\
0.423 \\
0.090 \\
(1.037) \\
\end{array}$ & $\begin{array}{c}1.027 \\
0.180 \\
0.179 \\
0.060 \\
(1.880) \\
\end{array}$ & $\begin{array}{r}6.383 \\
0.706 \\
0.581 \\
0.939 \\
(7.029) \\
\end{array}$ \\
\hline $\begin{array}{l}\text { weekly } \\
\text { mean } * 100 \\
\text { std. dev. } * 100 \\
\text { std. dev. } * 100 \text { detrended } \\
\text { linear trend } * 10^{5}\end{array}$ & $\begin{array}{c}1.897 \\
0.728 \\
0.728 \\
0.003 \\
(0.024) \\
\end{array}$ & $\begin{array}{c}1.218 \\
0.210 \\
0.209 \\
0.053 \\
(1.309) \\
\end{array}$ & $\begin{array}{c}5.842 \\
0.638 \\
0.555 \\
0.737 \\
(5.132) \\
\end{array}$ & $\begin{array}{c}1.858 \\
0.623 \\
0.623 \\
-0.017 \\
(-0.141) \\
\end{array}$ & $\begin{array}{c}1.218 \\
0.210 \\
0.209 \\
0.053 \\
(1.309) \\
\end{array}$ & $\begin{array}{r}5.842 \\
0.638 \\
0.554 \\
0.737 \\
(5.132)\end{array}$ \\
\hline $\begin{array}{l}\text { monthly } \\
\text { mean } * 100 \\
\text { std. dev. } * 100 \\
\text { std. dev. } * 100 \text { detrended } \\
\text { linear trend } * 10^{5}\end{array}$ & $\begin{array}{l}\mathrm{N} / \mathrm{A} \\
\mathrm{N} / \mathrm{A} \\
\mathrm{N} / \mathrm{A} \\
\mathrm{N} / \mathrm{A} \\
(\mathrm{N} / \mathrm{A})\end{array}$ & $\begin{array}{c}1.269 \\
0.298 \\
0.298 \\
0.026 \\
(0.518) \\
\end{array}$ & $\begin{array}{c}5.039 \\
0.636 \\
0.557 \\
0.720 \\
(5.950) \\
\end{array}$ & $\begin{array}{l}\mathrm{N} / \mathrm{A} \\
\mathrm{N} / \mathrm{A} \\
\mathrm{N} / \mathrm{A} \\
\mathrm{N} / \mathrm{A} \\
(\mathrm{N} / \mathrm{A})\end{array}$ & $\begin{array}{c}1.269 \\
0.298 \\
0.298 \\
0.026 \\
(0.518) \\
\end{array}$ & $\begin{array}{r}5.039 \\
0.636 \\
0.557 \\
0.720 \\
(5.950) \\
\end{array}$ \\
\hline $\begin{array}{l}\text { daily - large Firms } \\
\text { mean } * 100 \\
\text { std. dev. } * 100 \\
\text { std. dev. } * 100 \text { detrended } \\
\text { linear trend } * 10^{5}\end{array}$ & $\begin{array}{c}1.599 \\
1.061 \\
1.058 \\
0.185 \\
(1.454) \\
\end{array}$ & $\begin{array}{c}1.090 \\
0.203 \\
0.200 \\
0.087 \\
(2.601) \\
\end{array}$ & $\begin{array}{c}5.877 \\
0.771 \\
0.738 \\
0.524 \\
(3.375) \\
\end{array}$ & $\begin{array}{c}1.145 \\
0.435 \\
0.433 \\
0.116 \\
(1.254) \\
\end{array}$ & $\begin{array}{l}1.086 \\
0.195 \\
0.190 \\
0.085 \\
(2.563) \\
\end{array}$ & $\begin{array}{c}5.828 \\
0.638 \\
0.602 \\
0.499 \\
(3.286)\end{array}$ \\
\hline $\begin{array}{l}\text { daily - EW } \\
\text { mean } * 100 \\
\text { std. dev. } * 100 \\
\text { std. dev. } * 100 \text { detrended } \\
\text { linear trend } * 10^{5}\end{array}$ & $\begin{array}{c}1.211 \\
0.756 \\
0.754 \\
-0.114 \\
(-1.409)\end{array}$ & $\begin{array}{l}1.251 \\
0.160 \\
0.160 \\
0.022 \\
(0.515)\end{array}$ & $\begin{array}{c}33.903 \\
6.672 \\
4.075 \\
12.386 \\
(9.308)\end{array}$ & $\begin{array}{c}1.149 \\
0.496 \\
0.492 \\
-0.145 \\
(-1.975)\end{array}$ & $\begin{array}{l}1.251 \\
0.119 \\
0.160 \\
0.022 \\
(0.515)\end{array}$ & $\begin{array}{c}33.903 \\
6.672 \\
4.075 \\
12.386 \\
(9.308)\end{array}$ \\
\hline
\end{tabular}

Notes: see next page 
Note: Descriptive statistics and linear trend regression based on monthly data. Means and standard deviations are annualized. The trend regression $\sigma_{t}^{2}=\alpha+\beta t+\epsilon_{t}$ is estimated using OLS with NeweyWest corrected $t$-statistics. The bottom panel is based on an equal-weighting scheme (denoted EW) as opposed to a value-weighting for all other results. The panel denoted 'large Firms' uses only the 2026 (the total number of firms in 7/62) largest firms in each month (based on market capitalization). 
TABLE 3

Correlation Structure

\begin{tabular}{c|ccc|ccc} 
& \multicolumn{3}{c}{ raw } & \multicolumn{3}{c}{ detrended } \\
& MKT & IND & FIRM & MKT & IND & FIRM \\
\hline contemporaneous & 1.000 & 0.645 & 0.708 & 1.000 & 0.641 & 0.800 \\
correlation & & 1.000 & 0.705 & & 1.000 & 0.767 \\
& & & 1.000 & & & 1.000 \\
\hline autocorrelation & & & & & & \\
$\rho_{1}$ & 0.494 & 0.591 & 0.776 & 0.490 & 0.583 & 0.670 \\
$\rho_{2}$ & 0.383 & 0.463 & 0.727 & 0.378 & 0.453 & 0.600 \\
$\rho_{3}$ & 0.313 & 0.438 & 0.686 & 0.309 & 0.428 & 0.543 \\
$\rho_{4}$ & 0.160 & 0.415 & 0.584 & 0.154 & 0.404 & 0.394 \\
$\rho_{6}$ & 0.183 & 0.384 & 0.572 & 0.178 & 0.373 & 0.380 \\
$\rho_{12}$ & 0.087 & 0.316 & 0.471 & 0.083 & 0.306 & 0.253 \\
\hline
\end{tabular}

Note: Table reports the correlation structure of monthly volatility measures constructed from daily data (winsorized). 
TABLE 4

Mean and Variance Decomposition

\begin{tabular}{cc|ccc} 
& & MKT & IND & FIRM \\
\hline Mean - raw & with trend & & & \\
& $7 / 62-12 / 97$ & 0.160 & 0.116 & 0.724 \\
& $7 / 62-6 / 71$ & 0.162 & 0.126 & 0.712 \\
& $1 / 88-12 / 97$ & 0.134 & 0.097 & 0.769 \\
\hline Variance & detrended & & & \\
raw & MKT & 0.149 & 0.081 & 0.328 \\
& IND & & 0.027 & 0.133 \\
& FIRM & & & 0.282 \\
\hline \multirow{2}{*}{ Cond. Expect. } & MKT & 0.099 & 0.067 & 0.334 \\
& IND & & 0.026 & 0.137 \\
& FIRM & & & 0.337 \\
\hline
\end{tabular}

Note: Entries are the shares in the total mean and variance of a typical stock computed from

$$
1=E\left(M K T_{t}\right) / E \sigma_{r t}^{2}+E\left(I N D_{t}\right) / E \sigma_{r t}^{2}+E\left(F I R M_{t}\right) / E \sigma_{r t}^{2}
$$

for the mean and

$$
\begin{aligned}
1 & =\operatorname{var}\left(M K T_{t}\right) / \operatorname{var}\left(\sigma_{r t}^{2}\right)+\operatorname{var}\left(I N D_{t}\right) / \operatorname{var}\left(\sigma_{r t}^{2}\right)+\operatorname{var}\left(F I R M_{t}\right) / \operatorname{var}\left(\sigma_{r t}^{2}\right) \\
& +2 \operatorname{cov}\left(M K T_{t}, I N D_{t}\right) / \operatorname{var}\left(\sigma_{r t}^{2}\right)+2 \operatorname{cov}\left(M K T_{t}, F I R M_{t}\right) / \operatorname{var}\left(\sigma_{r t}^{2}\right) \\
& +2 \operatorname{cov}\left(I N D_{t}, F I R M_{t}\right) / \operatorname{var}\left(\sigma_{r t}^{2}\right) .
\end{aligned}
$$

for the variance. All series are monthly constructed from daily data and are winsorized. Unless otherwise noted, results based on the full sample (7/62-12/97) are reported. Conditional expectations are formed by regressing each volatility series on four lags of all three volatility series. 
TABLE 5

Granger-Causality

Bivariate VAR

\begin{tabular}{c|ccc} 
& $\mathrm{MKT}_{t}$ & $\mathrm{IND}_{t}$ & $\mathrm{FIRM}_{t}$ \\
\hline $\mathrm{MKT}_{t-l}$ & - & 0.000 & 0.000 \\
& & $(5)$ & $(4)$ \\
$\mathrm{IND}_{t-l}$ & 0.548 & - & 0.472 \\
& $(5)$ & & $(5)$ \\
$\mathrm{FIRM}_{t-l}$ & 0.008 & 0.002 & - \\
& $(2)$ & $(5)$ & \\
\hline
\end{tabular}

Trivariate VAR

\begin{tabular}{c|ccc} 
& $\mathrm{MKT}_{t T}$ & $\mathrm{IND}_{t}$ & $\mathrm{FIRM}_{t}$ \\
\hline $\mathrm{MKT}_{t-l}$ & - & 0.027 & 0.004 \\
$\mathrm{IND}_{t-l}$ & 0.416 & - & 0.155 \\
$\mathrm{FIRM}_{t-l}$ & 0.016 & 0.108 & - \\
& $(4)$ & $(5)$ & $(5)$ \\
\hline
\end{tabular}

Note: The table reports $p$-values of Granger-causality VAR tests. The optimal lag-length (shown in brackets) is chosen using the Akaike information criterion. The data is detrended and winsorized. 


\section{TABLE 6}

Cyclical Behavior: Correlation with NBER dates expansion: $\mathrm{n}_{t}=1$, contractions: $\mathrm{n}_{t}=0$

\begin{tabular}{c|ccc|ccc|ccc}
$\rho\left(\sigma_{t+j}^{2}, \mathrm{n}_{t}\right)$ & \multicolumn{3}{|c}{ MKT } & \multicolumn{3}{c}{ IND } & \multicolumn{3}{c}{ FIRM } \\
$($ months $)$ & $\sigma_{t}^{2}$ & $E_{t-1} \sigma_{t}^{2}$ & $\xi_{t}$ & $\sigma_{t}^{2}$ & $E_{t-1} \sigma_{t}^{2}$ & $\xi_{t}$ & $\sigma_{t}^{2}$ & $E_{t-1} \sigma_{t}^{2}$ & $\xi_{t}$ \\
\hline-12 & -0.091 & -0.075 & -0.063 & -0.208 & -0.178 & -0.120 & -0.125 & -0.080 & -0.098 \\
-6 & -0.162 & -0.149 & -0.098 & -0.320 & -0.310 & -0.155 & -0.230 & -0.196 & -0.126 \\
-3 & -0.354 & -0.346 & $\mathbf{- 0 . 1 9 8}$ & -0.436 & -0.454 & $\mathbf{- 0 . 1 8 2}$ & -0.434 & -0.363 & $\mathbf{- 0 . 2 4 6}$ \\
-1 & -0.413 & -0.466 & -0.192 & -0.461 & -0.518 & -0.159 & $\mathbf{- 0 . 5 1 5}$ & -0.487 & -0.230 \\
\hline 0 & $-\mathbf{0 . 4 2 0}$ & $-\mathbf{- 0 . 4 9 8}$ & -0.178 & $-\mathbf{0 . 4 7 2}$ & -0.529 & -0.164 & -0.508 & -0.525 & -0.180 \\
\hline+1 & -0.381 & -0.498 & -0.131 & -0.438 & $-\mathbf{0 . 5 3 3}$ & -0.116 & -0.477 & $\mathbf{- 0 . 5 2 9}$ & -0.129 \\
+3 & -0.316 & -0.417 & -0.099 & -0.328 & -0.425 & -0.094 & -0.399 & -0.452 & -0.098 \\
+6 & -0.248 & -0.322 & -0.085 & -0.280 & -0.335 & -0.076 & -0.330 & -0.368 & -0.085 \\
+12 & -0.083 & -0.135 & -0.008 & -0.163 & -0.170 & -0.066 & -0.175 & -0.192 & -0.046 \\
\hline
\end{tabular}

Correlation with GDP Growth

\begin{tabular}{c|ccc|ccc|ccc}
$\rho\left(\sigma_{t+j}^{2}, g_{t}\right)$ & \multicolumn{3}{|c}{ MKT } & \multicolumn{3}{c}{ IND } & \multicolumn{3}{c}{ FIRM } \\
$($ quarters $)$ & $\sigma_{t}^{2}$ & $E_{t-1} \sigma_{t}^{2}$ & $\xi_{t}$ & $\sigma_{t}^{2}$ & $E_{t-1} \sigma_{t}^{2}$ & $\xi_{t}$ & $\sigma_{t}^{2}$ & $E_{t-1} \sigma_{t}^{2}$ & $\xi_{t}$ \\
\hline-4 & -0.021 & -0.022 & -0.001 & -0.060 & -0.003 & -0.059 & -0.023 & 0.033 & -0.037 \\
-2 & -0.226 & -0.023 & -0.260 & -0.262 & -0.103 & -0.260 & -0.223 & -0.048 & -0.253 \\
-1 & $\mathbf{- 0 . 3 5 9}$ & -0.208 & $\mathbf{- 0 . 2 8 9}$ & -0.399 & -0.227 & $\mathbf{- 0 . 3 2 8}$ & $\mathbf{- 0 . 3 8 1}$ & -0.180 & $\mathbf{- 0 . 3 4 5}$ \\
\hline 0 & -0.321 & -0.335 & -0.162 & $\mathbf{- 0 . 4 1 2}$ & -0.368 & -0.214 & -0.342 & $\mathbf{- 0 . 3 4 1}$ & -0.146 \\
\hline+1 & -0.258 & $\mathbf{- 0 . 3 6 9}$ & -0.073 & -0.328 & $\mathbf{- 0 . 3 6 9}$ & -0.102 & -0.297 & -0.312 & -0.114 \\
+2 & -0.216 & -0.352 & -0.038 & -0.214 & -0.324 & 0.006 & -0.235 & -0.292 & -0.053 \\
+4 & -0.151 & -0.278 & 0.033 & -0.254 & -0.285 & -0.073 & -0.195 & -0.262 & -0.018 \\
\hline
\end{tabular}

Note: The volatility measures are detrended and exclude the crash. The panel reporting correlation with NBER dates is based on monthly data while the panel with GDP correlation is based on quarterly data (both constructed from daily returns). The three entries for each volatility measure are computed from $\sigma_{T}^{2}=E_{T-1} \sigma_{T}^{2}+\xi_{T}$ where the conditional expectations are formed by regressing each volatility series on four lags of all three volatility series. The largest values (in absolute value) for each column are written in bold. The data is detrended and winsorized. 
TABLE 7

Cyclical Behavior: GDP growth

\begin{tabular}{ccccc|c}
$\mathrm{GDP}_{t-1}$ & $\mathrm{RVW}_{t-1}$ & $\mathrm{MKT}_{t-1}$ & $\mathrm{IND}_{t-1}$ & $\mathrm{FIRM}_{t-1}$ & $R^{2}(p$-value $)$ \\
\hline 0.330 & 0.020 & & & & 0.143 \\
$(4.200)$ & $(2.548)$ & & & & \\
\hline 0.251 & 0.012 & -0.701 & & & 0.190 \\
$(2.947)$ & $(1.367)$ & $(-2.383)$ & & & \\
0.211 & 0.015 & & -1.841 & & 0.213 \\
$(2.270)$ & $(1.762)$ & & $(-2.432)$ & & \\
0.238 & 0.014 & & & -0.477 & 0.206 \\
$(2.536)$ & $(1.583)$ & & & $(-2.999)$ & \\
\hline 0.199 & 0.013 & -0.314 & -1.470 & & 0.219 \\
$(2.308)$ & $(1.415)$ & $(-0.883)$ & $(-1.625)$ & & $(0.002)$ \\
0.236 & 0.013 & -0.073 & & -0.441 & 0.206 \\
$(2.561)$ & $(1.659)$ & $(-0.180)$ & & $(-1.710)$ & $(0.008)$ \\
0.201 & 0.013 & & -1.239 & -0.250 & 0.222 \\
$(2.339)$ & $(1.481)$ & & $(-1.184)$ & $(-0.997)$ & $(0.002)$ \\
\hline 0.200 & 0.013 & -0.058 & -1.237 & -0.222 & 0.222 \\
$(2.135)$ & $(1.532)$ & $(-0.138)$ & $(-1.249)$ & $(-0.735)$ & $(0.006)$ \\
\hline
\end{tabular}

Note: The table reports results of various OLS regressions with GDP growth as the dependent variable. The respective regressors are lagged by one quarter. RVW denotes the return of the CRSP value-weighted portfolio. The $p$-values in the last column are for an $F$-test of joint significance of the volatility measures. All $t$-statistics in parentheses are computed using Newey-West standard errors. The volatility are quarterly constructed from daily returns, detrended and winsorized. 


\section{TABLE 9}

Individual Industries

\begin{tabular}{lcc|cccc|cccc} 
& \multicolumn{1}{l|}{} & \multicolumn{6}{|c|}{ IND } \\
Industry & weight & $\beta$ & mean & s.d. & trend & $t$-stat & mean & s.d. & trend & $t$-stat \\
\hline Petroleum/Gas & 11.031 & 0.86 & 1.013 & 0.302 & 0.249 & 5.683 & 5.498 & 0.774 & 0.583 & 2.864 \\
Fin. Services & 7.833 & 0.97 & 0.362 & 0.102 & -0.125 & -6.422 & 6.361 & 0.871 & 0.224 & 0.835 \\
Utilities & 7.446 & 0.66 & 0.311 & 0.097 & 0.033 & 2.295 & 4.032 & 0.500 & 0.125 & 0.993 \\
Consumer Goods & 6.117 & 1.02 & 0.562 & 0.122 & 0.016 & 0.700 & 4.590 & 0.598 & -0.006 & -0.043 \\
Telecomm. & 5.699 & 0.70 & 0.811 & 0.176 & -0.065 & -2.166 & 3.729 & 0.826 & 1.555 & 10.259 \\
Computer & 4.995 & 1.06 & 1.654 & 0.398 & 0.070 & 1.075 & 6.123 & 1.536 & 2.867 & 9.068 \\
Retail & 4.596 & 1.09 & 0.586 & 0.132 & 0.049 & 2.070 & 7.332 & 0.919 & 1.367 & 9.162 \\
Auto & 4.295 & 1.02 & 1.115 & 0.231 & 0.138 & 3.557 & 4.862 & 0.695 & 0.754 & 5.336 \\
Pharmaceutical & 4.206 & 1.00 & 0.792 & 0.228 & 0.167 & 3.158 & 6.126 & 0.745 & 0.780 & 5.043 \\
Chemical & 3.812 & 1.05 & 0.517 & 0.103 & 0.077 & 4.906 & 5.281 & 0.618 & 0.448 & 2.762 \\
\hline
\end{tabular}

Note: This table reports statistics of industry and firm dispersion measures for the ten largest individual industries. The industry measure is constructed using (26), the firm component according to (27). Means and standard deviations are annualized (in \%). The columns labeled 'trend' reports the OLS coefficient of the volatility series on a linear time trend and a constant. The t-statistics are Newey-West corrected. For IND, 16 (12) out of the 49 industries have a significantly positive (negative) trend. For FIRM, the corresponding numbers are 27 (4). 


\section{TABLE 10}

Correlation of Volatility Measures with Industry Output volatility measures converted to annual data

\begin{tabular}{l|cc|cc} 
& \multicolumn{2}{|c}{ IND } & \multicolumn{2}{c}{ FIRM } \\
Industry & contemporaneous & lagged & contemporaneous & lagged \\
\hline Petroleum/Gas & -0.297 & -0.132 & -0.165 & -0.270 \\
Fin. Services & -0.153 & 0.090 & -0.332 & -0.042 \\
Utilities & -0.153 & -0.032 & -0.094 & 0.020 \\
Consumer Goods & -0.290 & -0.308 & -0.201 & -0.272 \\
Telecomm. & -0.142 & -0.124 & -0.457 & -0.176 \\
Computer & -0.021 & 0.109 & 0.162 & 0.303 \\
Retail & -0.287 & -0.212 & -0.215 & -0.305 \\
Auto & -0.272 & 0.245 & -0.308 & 0.133 \\
Pharmaceutical & -0.045 & -0.108 & 0.281 & -0.054 \\
Chemical & 0.101 & -0.002 & -0.139 & 0.018 \\
\hline
\end{tabular}

Note: This table reports correlations of contemporaneous and lagged annualized volatility of the ten largest industries with output residuals in the respective industry. The residuals are computed from OLS regressions of industry output on aggregate industrial production. The output data is annual and ranges from 1972-97 (obtained from the BLS). Output data for industry 23 (miscellaneous manufacturing) was not available. For IND, 18 (5) out of the 49 industries have a significantly negative (positive) contemporaneous correlation with industry output, for 15 (3) the correlation of lagged IND with output is negative (positive). For FIRM, the corresponding numbers are 21 (3) and 18 (3), respectively. 

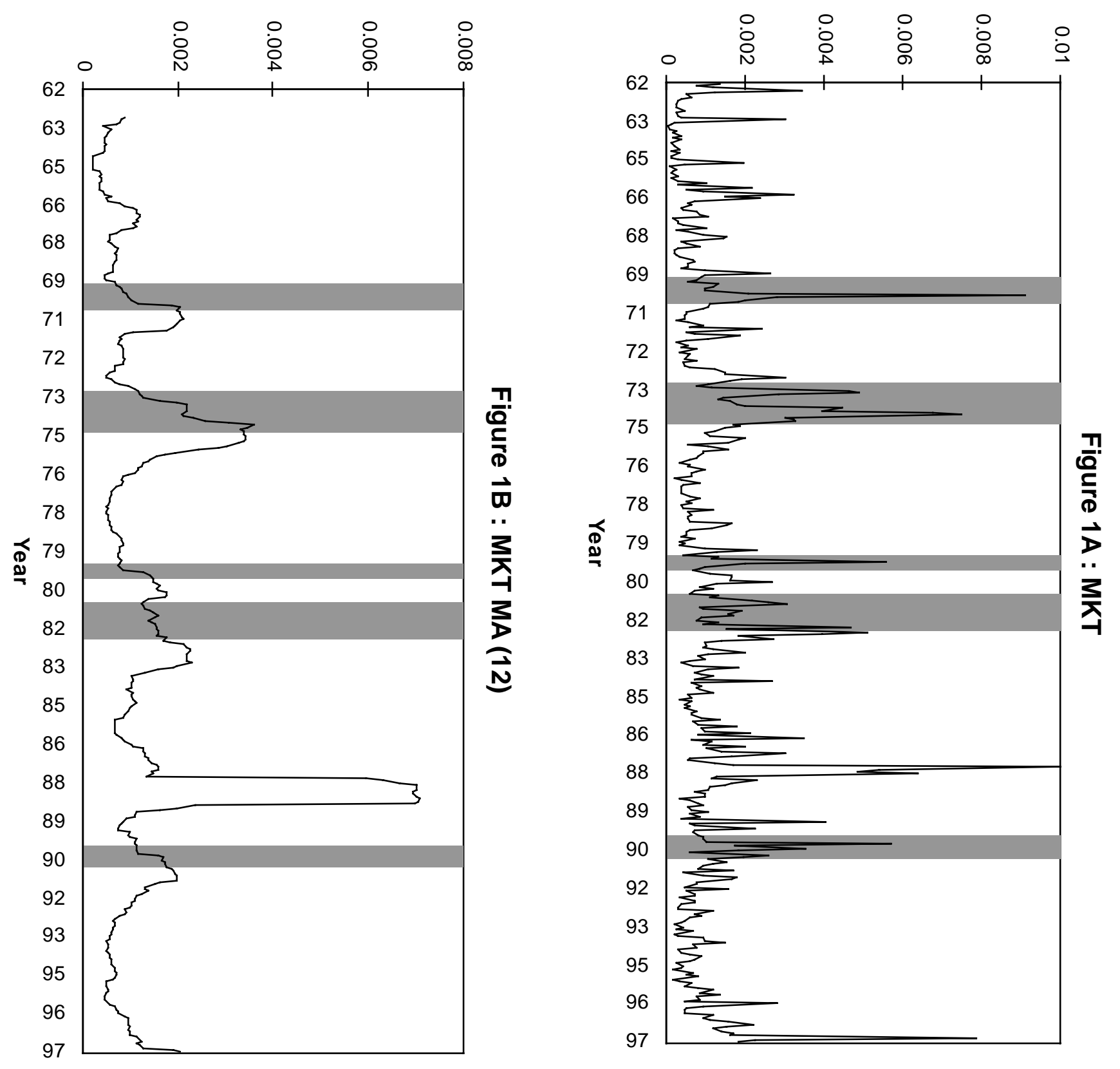

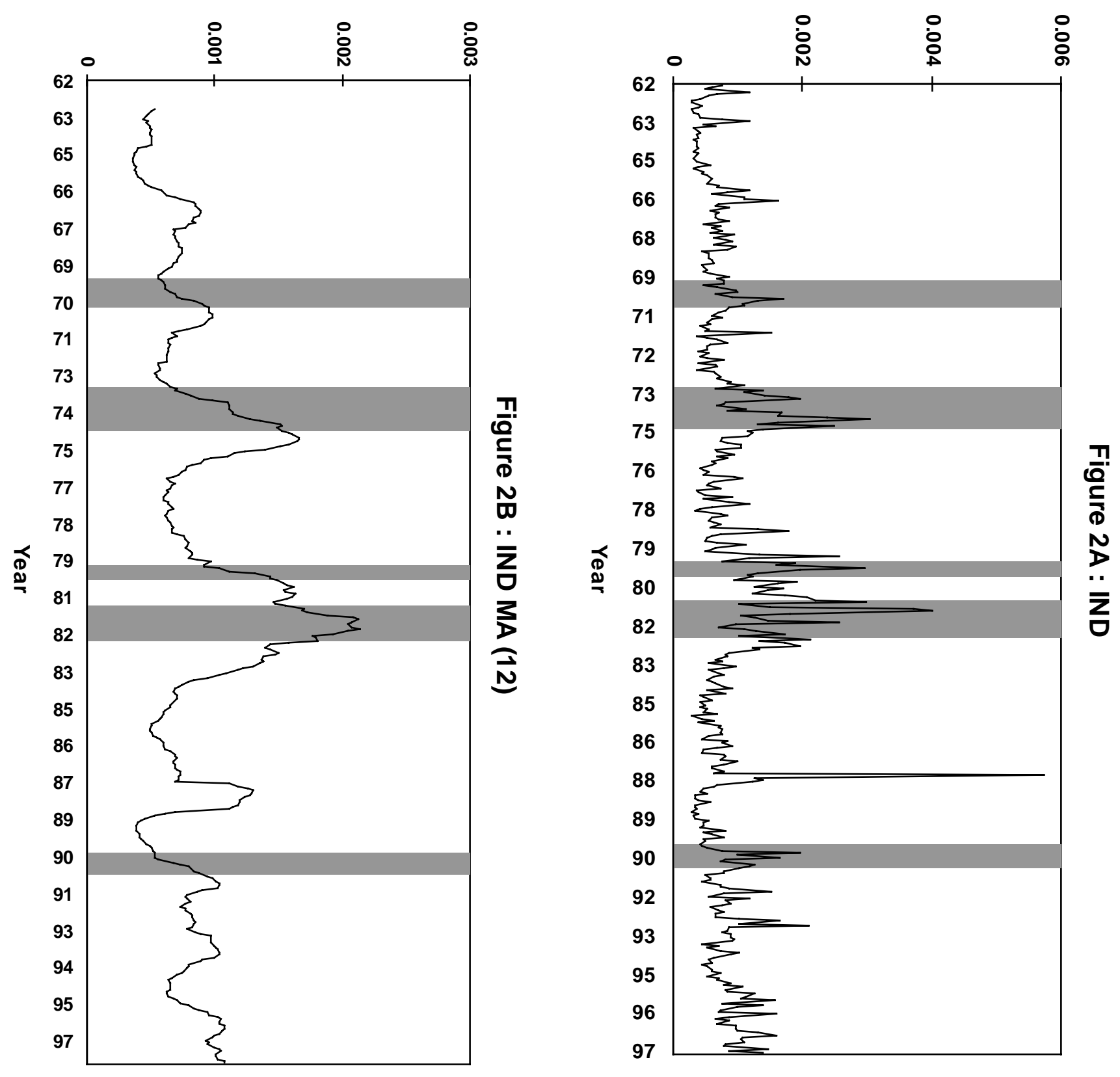

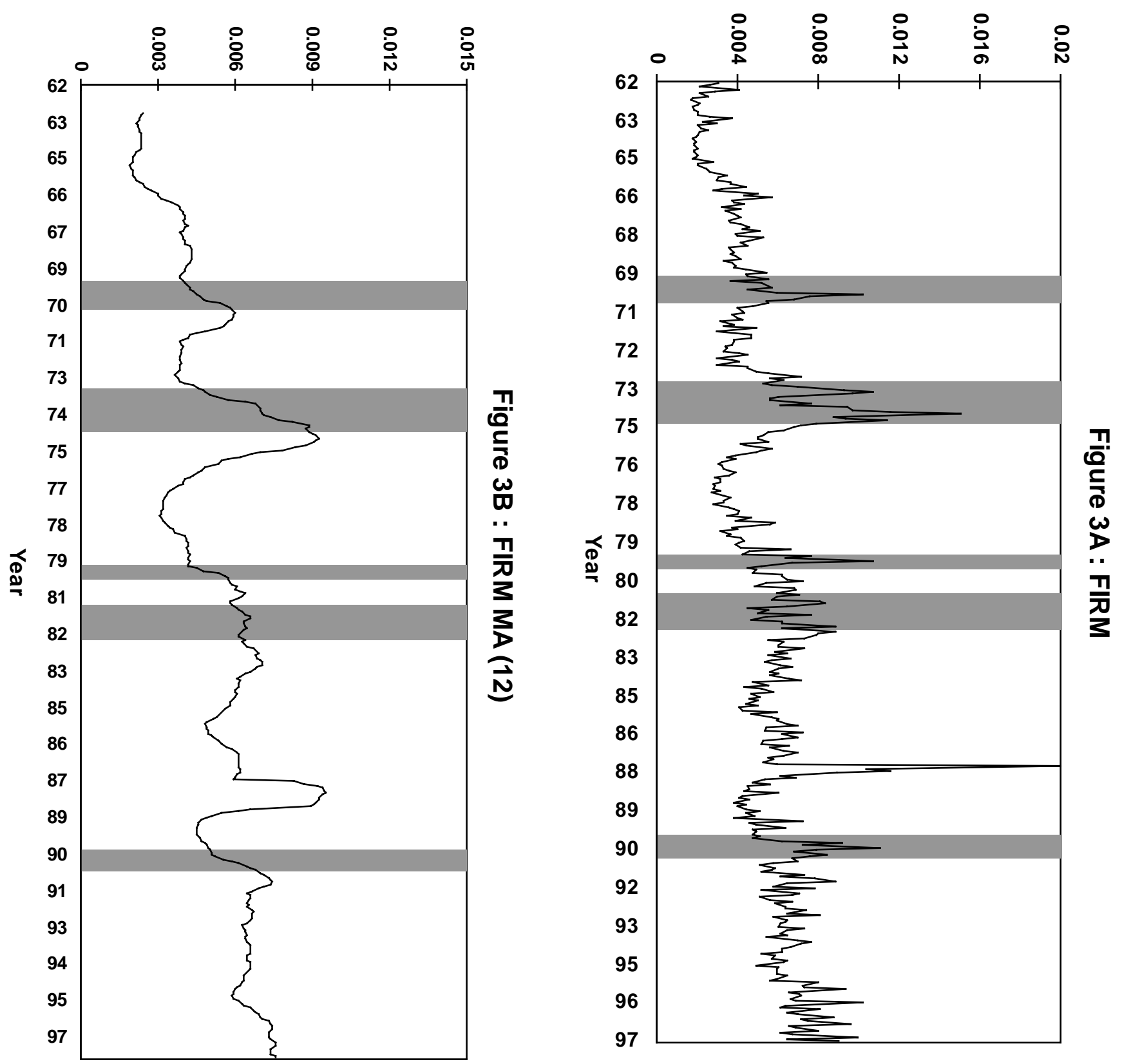